\title{
The CYP17A1 rs743572 Gene Polymorphism and Risk of Development and Clinical Features of Acne Vulgaris in the Uzbek Population
}

\author{
Nilufar N. Malikova ${ }^{1 *}$; Khamid Ya. Karimov, PhD, ScD \\ Kodirjon T. Boboev, $\mathrm{PhD}, \mathrm{ScD}^{2}$; Saidkasim S. Arifov, $\mathrm{PhD}, \mathrm{ScD}^{3}$ \\ ${ }^{1}$ Republican Dermatovenerologic Clinical Hospital \\ ${ }^{2}$ Scientific Research Institute of Hematology and Blood Transfusion \\ ${ }^{3}$ Tashkent Institute of Postgraduate Medical Education \\ Tashkent, Uzbekistan
}

\begin{abstract}
The purpose of this study was to analyze the association between the CYP17A1 rs743572 SNP and the development and clinical course of acne vulgaris (AV) in the Uzbek population.

The study included $165 \mathrm{AV}$ patients aged from 18 to 30 years (Group AV). All patients were divided into 3 subgroups in accordance with the severity of the disease. SAV1 included 59(35.8\%) patients with a mild degree of AV, SAV2 included 64(38.8\%) patients with a moderate degree of AV, and SAV3 included 42(25.4\%) patients with a severe degree of AV. The control group (CG) consisted of 97 healthy volunteers without a burdened dermatological history. The study revealed a significant association of the CYP17A1 rs743572 SNP with the risk of AV development in the Uzbek population. The study results showed that the presence of the A2 allele and A2/A2 genotype of the CYP17A1 rs743572 SNP might be a risk factor for AV in Uzbek ethnicity. It is obvious that the A1/A1 genotype of the CYP17A1 rs743572 SNP can have a protective effect not only in the formation of AV, but also in the severity of the disease. The functionally unfavorable A1/A2 genotype of the CYP17A1 rs743572 SNP is more characteristic of patients with a moderate degree of $\mathrm{AV}$, and the homozygote minor allele genotype $\mathrm{A} 2 / \mathrm{A} 2$ is more characteristic of patients with a severe degree of AV.(International Journal of Biomedicine. 2019;9(2):125-127.)
\end{abstract}

Key Words: acne vulgaris $\bullet$ single nucleotide polymorphism $\bullet$ CYP17A1 gene $\bullet$ rs 743572

\section{Abbreviations}

SNP, single nucleotide polymorphism; RMI, recessive model of inheritance; DMI, dominant model of inheritance; GMI, general model of inheritance

\section{Introduction}

Acne vulgaris (AV) is a polymorphic, multifactorial, chronic relapsing inflammatory disease of the sebaceous glands and hair follicles. Epidemiological studies have shown that the prevalence of acne among adolescents and young people reaches of $80 \%-90 \%$. However, the disease can occur in infants

"Corresponding author: Dr. Nilufar B. Malikova, Republican Dermatovenerologic Clinical Hospital of the Ministry of Health of the Republic of Uzbekistan, Tashkent, Uzbekistan. E-mail: dr.malikova@gmail.com and older adults. ${ }^{(1,2)} \mathrm{AV}$ has a multifactorial pathogenesis, of which the key factors are genetic predisposition and hormonal abnormalities (androgens play the key role). ${ }^{(3)}$

Cytochrome P450 family 17 (CYP17) is one of the key enzymes for the steroidogenic pathway. ${ }^{(4-6)} \mathrm{CYP} 17$ is encoded by the CYP17A1 gene, which is located on the long arm of chromosome 10q24.32. ${ }^{(7)}$ The enzyme mediates steroid $17 \alpha$-hydrolase and 17 , 20 -lyase activity in the endoplasmic reticulum. ${ }^{(8)} \mathrm{SNP}$ (гs743572) (a common single base pair substitution $[-34 \mathrm{~T} \rightarrow \mathrm{C}]$ ) in the 5'-untranslated region of the CYP17A1 gene is widely studied, but the functional impact of the T/C change is presently, to our knowledge, not known. The common $\mathrm{T}$ allele is referred as A1 
and the variant $\mathrm{C}$ allele as $\mathrm{A} 2$. The minor allele $\mathrm{A} 2$, compared to $\mathrm{A} 1$, is postulated to correlate with higher serum levels of various sex steroids in some studies. ${ }^{(9,10)}$

The purpose of this study was to analyze the association between the CYP17A1 rs743572 SNP and the development and clinical course of $\mathrm{AV}$ in the Uzbek population.

\section{Materials and Methods}

The study included $165 \mathrm{AV}$ patients aged from 18 to 30 years (Group AV). All patients were divided into 3 subgroups in accordance with the severity of the disease. SAV1 included $59(35.8 \%)$ patients with a mild degree of AV, SAV2 included 64(38.8\%) patients with a moderate degree of AV, and SAV3 included $42(25.4 \%)$ patients with a severe degree of AV. The control group (CG) consisted of 97 healthy volunteers without a burdened dermatological history. The groups were comparable in sex and age. We used the standard method for analysis of case-control data.

Genomic DNA was isolated from the peripheral blood leukocytes using a modified phenol-chloroform extraction method. ${ }^{(1)}$ PCR was performed in Rotor Gene 6000 (Corbett Research, Australia) using Sintol reagent kits (Russia) according to the manufacturer's instructions (Table 1, Fig. 1).

Table 1.

Polymerase chain reaction amplification conditions

\begin{tabular}{|c|c|c|c|c|}
\hline Step & Temperature & Time & Detection & Repeats \\
\hline Hold & 94 & $3 \mathrm{~min}$ & No acquiring & 1 \\
\hline \multirow{3}{*}{ Cycling 1} & 94 & $20 \mathrm{sec}$ & No acquiring & \multirow{3}{*}{10} \\
\hline & 58 & $20 \mathrm{sec}$ & No acquiring & \\
\hline & 61 & $30 \mathrm{sec}$ & No acquiring & \\
\hline \multirow{3}{*}{ Cycling 2} & 94 & $20 \mathrm{sec}$ & No acquiring & \multirow{3}{*}{30} \\
\hline & 58 & $20 \mathrm{sec}$ & No acquiring & \\
\hline & 61 & $30 \mathrm{sec}$ & $\begin{array}{l}\text { Acquiring on } \\
\text { Green, Yellow }\end{array}$ & \\
\hline
\end{tabular}

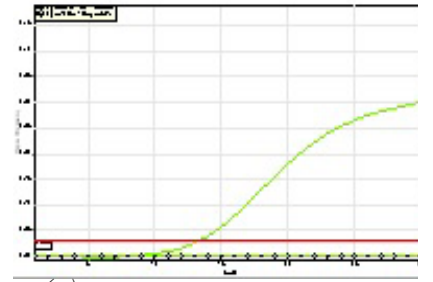

(a)

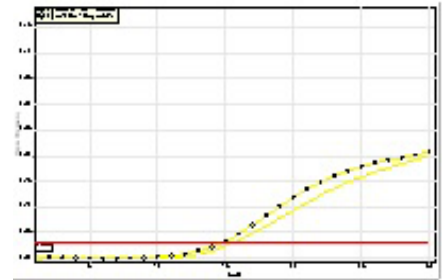

(b)

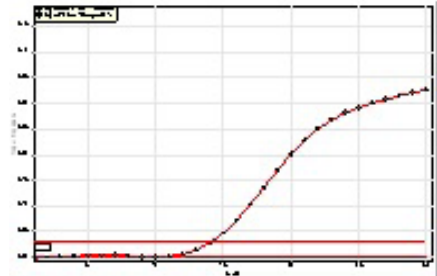

(c)
Fig. 1. The results of real-time PCR for the CYP17A1 rs743572 SNP (a)-homozygous wild-type; (b)-heterozygous mutant; (c)-homozygous mutant.
Statistical data processing was performed using OpenEpi 2009, Version 2.3. Deviation from Hardy-Weinberg equilibrium and differences in allele distributions between the two groups were assessed by $\chi 2$ - test with 1 degree of freedom (df). Odds ratios (ORs) and 95\% confidence intervals (CIs) were calculated. Chi-square test was used to assess the categorical variables. A probability value of $P<0.05$ was considered statistically significant.

The study was approved by our Institutional Ethics Committee. Written informed consent was obtained from each patient.

\section{Results and Discussion}

The frequency of genotypes and alleles of the CYP17A1 rs743572 SNP in the studied groups is presented in Table 2. The distribution of the genotype frequency was in HWE for both groups $(P>0.05)$. In Groups $\mathrm{AV}$ and $\mathrm{CG}$, the frequencies of the A1 and A2 alleles were as follows: $56.7 \%$ and $43.3 \%$ versus $80.4 \%$ and $19.6 \%$, respectively. We further used the 3 types of genetic models to test the association between the CYP17A1 rs743572 SNP and AV. We found a significant prevalence of the carriage of the minor A2 allele in Group $\mathrm{AV}$, compared to $\mathrm{CG}\left(\chi^{2}=30.5 ; P<0.05 ; \mathrm{OR}=3.14 ; 95 \% \mathrm{CI}\right.$ : 2.07-4.76). The frequency distribution of the A1/A1, A1/A2 and $\mathrm{A} 2 / \mathrm{A} 2$ genotypes in Groups $\mathrm{AV}$ and $\mathrm{CG}$ were as follows: $33.9 \%, 45.5 \%$ and $20.6 \%$ versus $67.0 \%, 26.8 \%$ and $6.2 \%$, respectively. We found a significant prevalence of the carriage of the heterozygous genotype A1/A2 and homozygote minor allele genotype $\mathrm{A} 2 \mathrm{~A} 2$ in Group $\mathrm{AV}$, compared to $\mathrm{CG}\left(\chi^{2}=26.55 ; P<0.05 ; \mathrm{OR}=2.28 ; 95 \% \mathrm{CI}: 1.35-3.92\right.$; and $\mathrm{OR}=3.94 ; 95 \%$ CI: $1.59-9.76$ ). The frequency of the wild A1/ A1 genotype in Group AV was significantly lower than in CG, which may indicate a protective effect of this genotype for the development of $\mathrm{AV}(\mathrm{OR}=0.25$; 95\% CI: $0.15-0.43)$.

\section{Table 2.}

The frequency of genotypes and alleles of the CYP17A1 rs743572 SNP in the studied groups

\begin{tabular}{|c|c|c|c|c|c|c|c|c|c|c|}
\hline \multirow{3}{*}{ Group } & \multicolumn{4}{|c|}{ Allele } & \multicolumn{6}{|c|}{ Genotype } \\
\hline & \multicolumn{2}{|c|}{ A1 } & \multicolumn{2}{|c|}{ A2 } & \multicolumn{2}{|c|}{ A1/A1 } & \multicolumn{2}{|c|}{$\mathrm{A} 1 / \mathrm{A} 2$} & \multicolumn{2}{|c|}{$\mathrm{A} 2 / \mathrm{A} 2$} \\
\hline & $\mathrm{n}$ & $\%$ & $\mathrm{n}$ & $\%$ & $\mathrm{n}$ & $\%$ & $\mathrm{n}$ & $\%$ & $\mathrm{n}$ & $\%$ \\
\hline Group AV & 187 & 56.7 & 143 & 43.3 & 56 & 33.9 & 75 & 45.5 & 34 & 20.6 \\
\hline SAV3 & 18 & 21.4 & 66 & 78.6 & 2 & 4.8 & 14 & 33.3 & 26 & 61.9 \\
\hline SAV2 & 70 & 54.7 & 58 & 45.3 & 13 & 20.3 & 44 & 68.7 & 7 & 10.9 \\
\hline SAV1 & 99 & 83.9 & 19 & 16.1 & 41 & 69.5 & 17 & 28.8 & 1 & 1.7 \\
\hline $\mathrm{CG}$ & 156 & 80.4 & 38 & 19.6 & 65 & 67.0 & 26 & 26.8 & 6 & 6.2 \\
\hline
\end{tabular}

In SAV3, the minor A2 allele was found approximately 5 times more often than in $\mathrm{CG}\left(\chi^{2}=87.1 ; P<0.05 ; \mathrm{OR}=15.05\right.$; $95 \%$ CI: 8.014-28.27). In contrast, the frequency of the A1/ A1 genotype was significantly lower than in $C G\left(\chi^{2}=45.5\right.$; $P<0.05$; OR $=0.02 ; 95 \%$ CI: $0.01-0.11)$. The carriage of the 
A2/A2 genotype was associated with an increased risk of a severe degree of AV in RMI $\left(\chi^{2}=51.3 ; P<0.05 ; \mathrm{OR}=24.6 ; 95 \%\right.$ CI: 8.76-69.35). The frequency of the heterozygous A1/A2 genotype was not significantly different than in CG.

In SAV2, the minor A2 allele was also significantly more frequent than in $\mathrm{CG}\left(\chi^{2}=24.4 ; P<0.05 ; \mathrm{OR}=3.4 ; 95 \%\right.$ C: I2.07-5.39). The carriage of the A1/A2 genotype was also associated with an increased risk of a moderate degree of AV in GMI $\left(\chi^{2}=34.04 ; P<0.05\right.$; OR=6.01; 95\% CI: 3.00-12.02). There were no differences in the frequency distribution of the homozygous A2/A2 genotype between the patient sample and CG, and significant risk was not found in RMI $\left(\chi^{2}=1.17\right.$; $P=0.28$; OR=1.86; 95 \% CI: 0.60-5.82).

In SAV1, no significant differences were found in the frequency of the alleles and genotypes of the CYP17A1 rs 743572 SNP, compared to CG.

The distribution of alleles and genotypes of the CYP17A1 rs743572 SNP differed significantly depending on the severity of the clinical course of AV. It was found that the minor A2 allele was significantly more frequent in SAV3 than in SAV2 and $\operatorname{SAV} 1\left(\chi^{2}=75.721 ; P=0\right)$. It was also noted that the minor A2 allele was significantly more frequent in SAV2 than in SAV1 (45.3\% versus $16.1 \%$, respectively; $\chi^{2}=24.363$; $P=0.000$ ). A similar pattern with a more pronounced statistical significance was found in a comparative analysis of the distribution of the homozygous A2/A2 genotype. The A2/A2 genotype was significantly more frequent in SAV3 than in SAV2 and SAV1 $\left(\chi^{2}=60.341, P=0.000\right)$. The A2/A2 genotype was also significantly more frequent in SAV2 than in SAV1 $\left(\chi^{2}=4.313 ; P=0.038\right)$. The heterozygous A1/A2 genotype was significantly more frequent in SAV2 than in SAV3 and SAV1 $\left(\chi^{2}=23.087 ; P=0.0000\right)$. Differences in the frequency of the A1/ A1 genotype were also significant between SAV1 and SAV2 $\left(\chi^{2}=30.148 ; P=0.0000\right)$, as well as between SAV1 and SAV3 $\left(\chi^{2}=42.047 ; P=0.0000\right)$. It is obvious that the $\mathrm{A} 1 / \mathrm{A} 1$ genotype of the CYP17A1 rs743572 SNP can have a protective effect not only in the formation of $\mathrm{AV}$, but also in the severity of the disease.

Thus, the functionally unfavorable A1/A2 genotype of the CYP17A1 rs743572 SNP is more characteristic of patients with a moderate degree of $\mathrm{AV}$, and the homozygote minor allele genotype A2/A2 is more characteristic of patients with a severe degree of AV.

The role of the CYP17A1 rs743572 SNP in the formation and development of acne is not completely clear. Thus, in the Chinese and Iranian populations, there was higher acne risk related to CYP17 (T-34C), ${ }^{(12,13)}$ but in the Polish and Indonesian populations this risk was not found. ${ }^{(14,15)}$ Our study revealed a significant association of the CYP17A1 rs743572 SNP with the risk of AV development in the Uzbek population. The results of our study showed that the presence of the A2 allele and A2/A2 genotype of the CYP17A1 rs743572 SNP might be a risk factor for $\mathrm{AV}$ in Uzbek ethnicity. Obviously, populations and ethnic groups differ in the frequency of distribution of polymorphic variants of the CYP17A1 rs743572 SNP and their contribution to the development of various nosologies associated with an imbalance of sex hormones. Further studies need to obtain a more accurate result.

\section{Competing Interests}

The authors declare that they have no competing interests.

\section{References}

1. Goldberg DJ, Berlin AL. Acne and Rosacea: Epidemiology, Diagnosis, and Treatment. Manson Publishing LTD; 2012.

2. Spencer EH, Ferdowsian HR, Barnard ND. Diet and acne: a review of the evidence. Int J Dermatol. 2009;48(4):339-47. doi: 10.1111/j.1365-4632.2009.04002.x.

3. James WD. Clinical practice. Acne. N Engl J Med. 2005;352(14):1463-72.

4. Miller WL. Early steps in androgen biosynthesis: from cholesterol to DHEA. Baillieres Clin Endocrinol Metab. 1998;12(1):67-81.

5. Auchus RJ, Miller WL. Molecular modeling of human P450c17 (17alpha-hydroxylase/17,20-lyase): insights into reaction mechanisms and effects of mutations. Mol Endocrinol. 1999;13(7):1169-82.

6. Missaghian E, Kempná P, Dick B, Hirsch A, AlikhaniKoupaei R, Jégou B, Mullis PE, Frey BM, Flück CE. Role of DNA methylation in the tissue-specific expression of the CYP17A1 gene for steroidogenesis in rodents. J Endocrinol. 2009;202(1):99-109. doi: 10.1677/JOE-08-0353.

7. Fan YS, Sasi R, Lee C, Winter JS, Waterman MR, Lin CC. Localization of the human CYP17 gene (cytochrome P450(17 alpha)) to 10q24.3 by fluorescence in situ hybridization and simultaneous chromosome banding. Genomics. 1992;14(4):1110-1

8. Nguyen PT, Conley AJ, Sneyd J, Lee RS, Soboleva TK, Shorten PR.The role of enzyme compartmentalization on the regulation of steroid synthesis.J Theor Biol. 2013;332:52-64. doi: 10.1016/j.jtbi.2013.04.021.

9. Carey AH, Waterworth D, Patel K, White D, Little J, Novelli P, Franks S, Williamson R. Polycystic ovaries and premature male pattern baldness are associated with one allele of the steroid metabolism gene CYP17. Hum Mol Genet. 1994;3(10):1873-6.

10. Feigelson HS, Shames LS, Pike MC, Coetzee GA, Stanczyk FZ, Henderson BE. Cytochrome P450c17alpha gene (CYP17) polymorphism is associated with serum estrogen and progesterone concentrations. Cancer Res. 1998;58(4):585-7.

11. Sambrook J, Fritsch EF, Maniatis T. Molecular Cloning: A Laboratory Manual. Cold Spring Harbor NY; Cold Spring Harbor Lab Press; 1987.

12. He L, Yang Z, Yu H, Cheng B, Tang W, Dong Y, Xiao C. The relationship between CYP17 -34T/C polymorphism and acne in Chinese subjects revealed by sequencing. Dermatology. 2006;212(4):338-42.

13. Chamaie-Nejad F, Saeidi S, Najafi F, Ebrahimi A, Rahimi Z, Shakiba E, Rahimi Z. Association of the CYP17 MSP AI (T-34C) and CYP19 codon 39 (Trp/Arg) polymorphisms with susceptibility to acne vulgaris. Clin Exp Dermatol. 2018;43(2):183-186. doi: 10.1111/ced.13321.

14. Sobjanek M, Zabłotna M, Dobosz-Kawałko M, Michajłowski I, Mędrzycka-Dąbrowska W, Nowicki R, Sokołowska-Wojdyło M. Polymorphisms in the cytochrome P-450 (CYP) 1A1 and 17 genes are not associated with acne vulgaris in the Polish population. Postepy Dermatol Alergol. 2015;32(5):323-6. doi: 10.5114/pdia.2014.44004.

15. Anwar AI, Agusni I, Massi MN, Yusuf I. The Immunogenetic Analysis of Acne Vulgaris. Science Journal of Clinical Medicine. 2013;2(2):58-63. 